\title{
Association of Gestational Weight Gain With Adverse Maternal and Infant Outcomes
}

Citation for published version (APA):

Voerman, E., Santos, S., Inskip, H., Amiano, P., Barros, H., Charles, M-A., Chatzi, L., Chrousos, G. P., Corpeleijn, E., Crozier, S., Doyon, M., Eggesbo, M., Fantini, M. P., Farchi, S., Forastiere, F., Georgiu, V., Gori, D., Hanke, W., Hertz-Picciotto, I., ... Gaillard, R. (2019). Association of Gestational Weight Gain With Adverse Maternal and Infant Outcomes. JAMA-Journal of the American Medical Association, 321(17), 1702-1715. https://doi.org/10.1001/jama.2019.3820

Document status and date:

Published: 07/05/2019

DOI:

10.1001/jama.2019.3820

Document Version:

Publisher's PDF, also known as Version of record

Document license:

Taverne

Please check the document version of this publication:

- A submitted manuscript is the version of the article upon submission and before peer-review. There can be important differences between the submitted version and the official published version of record.

People interested in the research are advised to contact the author for the final version of the publication, or visit the DOI to the publisher's website.

- The final author version and the galley proof are versions of the publication after peer review.

- The final published version features the final layout of the paper including the volume, issue and page numbers.

Link to publication

\footnotetext{
General rights rights.

- You may freely distribute the URL identifying the publication in the public portal. please follow below link for the End User Agreement:

www.umlib.nl/taverne-license

Take down policy

If you believe that this document breaches copyright please contact us at:

repository@maastrichtuniversity.nl

providing details and we will investigate your claim.
}

Copyright and moral rights for the publications made accessible in the public portal are retained by the authors and/or other copyright owners and it is a condition of accessing publications that users recognise and abide by the legal requirements associated with these

- Users may download and print one copy of any publication from the public portal for the purpose of private study or research.

- You may not further distribute the material or use it for any profit-making activity or commercial gain

If the publication is distributed under the terms of Article $25 \mathrm{fa}$ of the Dutch Copyright Act, indicated by the "Taverne" license above, 


\title{
Association of Gestational Weight Gain With Adverse Maternal and Infant Outcomes
}

\author{
LifeCycle Project-Maternal Obesity and Childhood Outcomes Study Group
}

IMPORTANCE Both low and high gestational weight gain have been associated with adverse maternal and infant outcomes, but optimal gestational weight gain remains uncertain and not well defined for all prepregnancy weight ranges.

OBJECTIVES To examine the association of ranges of gestational weight gain with risk of adverse maternal and infant outcomes and estimate optimal gestational weight gain ranges across prepregnancy body mass index categories.

DESIGN, SETTING, AND PARTICIPANTS Individual participant-level meta-analysis using data from 196670 participants within 25 cohort studies from Europe and North America (main study sample). Optimal gestational weight gain ranges were estimated for each prepregnancy body mass index (BMI) category by selecting the range of gestational weight gain that was associated with lower risk for any adverse outcome. Individual participant-level data from 3505 participants within 4 separate hospital-based cohorts were used as a validation sample. Data were collected between 1989 and 2015. The final date of follow-up was December 2015.

EXPOSURES Gestational weight gain.

MAIN OUTCOMES AND MEASURES The main outcome termed any adverse outcome was defined as the presence of 1 or more of the following outcomes: preeclampsia, gestational hypertension, gestational diabetes, cesarean delivery, preterm birth, and small or large size for gestational age at birth.

RESULTS Of the 196670 women (median age, 30.0 years [quartile 1 and 3, 27.0 and 33.0 years] and 40937 were white) included in the main sample, 7809 (4.0\%) were categorized at baseline as underweight (BMI <18.5); 133788 (68.0\%), normal weight (BMI, 18.5-24.9); 38828 (19.7\%), overweight (BMI, 25.0-29.9); 11992 (6.1\%), obesity grade 1 (BMI, 30.0-34.9); 3284 (1.7\%), obesity grade 2 (BMI, 35.0-39.9); and 969 (0.5\%), obesity grade 3 (BMI, $\geq 40.0$ ). Overall, any adverse outcome occurred in 37.2\% ( $n=73161)$ of women, ranging from $34.7 \%$ (2706 of 7809 ) among women categorized as underweight to $61.1 \%$ (592 of 969) among women categorized as obesity grade 3. Optimal gestational weight gain ranges were $14.0 \mathrm{~kg}$ to less than $16.0 \mathrm{~kg}$ for women categorized as underweight; $10.0 \mathrm{~kg}$ to less than $18.0 \mathrm{~kg}$ for normal weight; $2.0 \mathrm{~kg}$ to less than $16.0 \mathrm{~kg}$ for overweight; $2.0 \mathrm{~kg}$ to less than $6.0 \mathrm{~kg}$ for obesity grade 1 ; weight loss or gain of $0 \mathrm{~kg}$ to less than $4.0 \mathrm{~kg}$ for obesity grade 2; and weight gain of $0 \mathrm{~kg}$ to less than $6.0 \mathrm{~kg}$ for obesity grade 3 . These gestational weight gain ranges were associated with low to moderate discrimination between those with and those without adverse outcomes (range for area under the receiver operating characteristic curve, 0.55-0.76). Results for discriminative performance in the validation sample were similar to the corresponding results in the main study sample (range for area under the receiver operating characteristic curve, 0.51-0.79).

CONCLUSIONS AND RELEVANCE In this meta-analysis of pooled individual participant data from 25 cohort studies, the risk for adverse maternal and infant outcomes varied by gestational weight gain and across the range of prepregnancy weights. The estimates of optimal gestational weight gain may inform prenatal counseling; however, the optimal gestational weight gain ranges had limited predictive value for the outcomes assessed.

JAMA. 2019;321(17):1702-1715. doi:10.1001/jama.2019.3820
Editor's Note page 1715

Supplemental content

CME Quiz at

jamanetwork.com/learning and CME Questions page 1722
Authors/Group Information: The LifeCycle Project-Maternal Obesity and Childhood Outcomes Study Group authors appear at the end of this article.

Corresponding Author: Romy Gaillard, MD, PhD, Generation R Study Group (Room Na-2908), Erasmus MC, University Medical Center, PO Box 2040, 3000 CA Rotterdam, the Netherlands (r.gaillard@erasmusmc.nl). 
G estational weight gain has been found to be related to the risk of pregnancy complications, maternal postpartum weight retention, and obesity in offspring. $.^{1-3} \mathrm{Ges}-$ tational weight gain reflects multiple characteristics, including maternal fat accumulation, fluid expansion, and the growth of the fetus, placenta, and uterus. ${ }^{4}$ Gestational weight gain is necessary to ensure a healthy fetus, but excessive gestational weight gain has been associated with adverse outcomes.

Higher prepregnancy body mass index (BMI; calculated as weight in kilograms divided by height in meters squared) also has been associated with lower gestational weight gain and increased risk for adverse maternal and infant outcomes. Therefore, optimal gestational weight gain ranges should account for prepregnancy BMI. ${ }^{5,6}$ Existing guidelines for gestational weight gain from the US National Academy of Medicine (NAM; formerly the Institute of Medicine) have limitations such as the reliance on a limited number of observational studies relating gestational weight gain to 5 maternal and offspring outcomes and insufficient information about important pregnancy outcomes (eg, gestational hypertension and gestational diabetes). ${ }^{7}$ In addition, the NAM guidelines do not include recommendations for obesity grade 1,2 , and 3 separately even though the prevalence of extreme obesity is increasing in Western populations. Information regarding optimal gestational weight gain across a range of maternal BMI categories is important for the identification of groups at increased risk.

This study pooled individual participant data from 25 pregnancy and birth cohorts from Europe and North America to assess associations of the amount of gestational weight gain with maternal and infant outcomes according to baseline weight status of underweight, normal weight, overweight, obesity grade1, obesity grade 2 , and obesity grade 3 .

\section{Methods}

\section{Inclusion Criteria and Participating Cohorts}

This study was part of an international LifeCycle Project collaboration on maternal obesity and childhood outcomes. ${ }^{8,9}$ A pregnancy or birth cohort study was eligible for inclusion if it included mothers with singleton live-born children who were born between 1989 and 2015, had information on maternal prepregnancy or early-pregnancy BMI, and had at least 1 offspring measurement (birth weight or childhood BMI). The final date of follow-up was December 2015. No exclusions were made based on previous pregnancy or birth complications.

The cohorts included had received institutional review board approval and written informed consent had been obtained. We invited 50 Western cohorts from Europe, North America, and Oceania that had been selected from existing collaborations on childhood health (the EarlyNutrition Project, the CHICOS Project, and Birthcohorts.net, which was accessed until July 2014), of which 39 cohorts agreed to participate. Only participants with information on maternal prepregnancy BMI, gestational weight gain, and at least 1 maternal or infant outcome of interest were included.

Of the 29 cohorts with the required data, 25 were populationbased cohorts and were included in the main study sample.

\section{Key Points}

Question What is the association of gestational weight gain (across a range of prepregnancy weights) with maternal and infant outcomes?

Findings In this meta-analysis of individual participant data from 25 pooled cohort studies and 196670 participants, prepregnancy weight and the magnitude of gestational weight gain were associated with risk for any adverse outcome (defined as $\geq 1$ of the following: preeclampsia, gestational hypertension, gestational diabetes, cesarean delivery, preterm birth, and small or large size for gestational age at birth); however, the magnitude of gestational weight gain was weakly associated with the adverse outcomes assessed.

Meaning These findings may inform prenatal counseling regarding optimal weight gain during pregnancy; however, the magnitude of gestational weight gain was weakly associated with the outcomes assessed.

The remaining 4 hospital-based cohorts were included as the external validation sample (eFigure 1 in the Supplement). The included cohorts and the data collection methods appear in eTable 1 the Supplement. Women could be included more than once in the analyses if they had multiple singleton pregnancies during the study period. Anonymized data sets were stored on a single central secure data server that was only accessible by the main investigator analysts (E.V. and R.G.).

\section{Maternal Prepregnancy BMI and Gestational Weight Gain} Maternal prepregnancy BMI was grouped into categories by 2 BMI units and clinical BMI groups according to World Health Organization definitions. ${ }^{10}$ Data on total gestational weight gain in kilograms, which was defined as the difference between the latest weight before delivery and the prepregnancy weight, were provided by the cohorts. Gestational weight gain was grouped into categories of $2 \mathrm{~kg}$ each, ranging from weight loss to weight gain of $28 \mathrm{~kg}$ or greater. Smaller increments of gestational weight gain were not used because of insufficient statistical power among underweight and severely obese women. Categories at the extremes of gestational weight gain were combined for maternal underweight, obesity grade 2 , and obesity grade 3 . To be included, women were required to have data for maternal prepregnancy BMI, total gestational weight gain, and any adverse outcome (defined below).

\section{Adverse Maternal and Infant Outcomes}

The main outcome of the analyses was the composite any adverse outcome, which was defined as the presence of at least 1 of the following outcomes: preeclampsia, gestational hypertension, gestational diabetes, cesarean delivery, preterm birth, and small or large size for gestational age at birth. Preterm birth was defined as gestational age at birth of less than 37 weeks. Sex- and gestational age-adjusted SD scores for birth weight were calculated using a Northern European reference chart. ${ }^{11}$ Small and large sizes for gestational age at birth were defined as sex- and gestational age-adjusted birth weight less than the 10th percentile and greater than the 90th percentile, respectively, within each cohort.

For the sensitivity analyses, sex- and age-adjusted SD scores were calculated for childhood BMI based on reference growth charts from the World Health Organization. ${ }^{12,13}$ The SD 
scores were obtained using data from the highest age available for each child (median age, 84.9 months [quartile 1 and 3, 61.9 and 95.9 months]) and categorized as underweight, normal weight, and overweight or obesity (referred to as overweight) using World Health Organization cutoffs. ${ }^{12,13}$

\section{Statistical Analysis}

Exploratory multilevel linear regression models were used to assess associations of maternal baseline characteristics with total gestational weight gain. The absolute risk for any adverse outcome was estimated across the full range of maternal prepregnancy BMI and gestational weight gain. Absolute risks were calculated as the percentage of women with any adverse outcome within each combination of BMI and gestational weight gain categories. Similarly, the absolute risks were estimated for any adverse outcome and for each individual outcome across the range of gestational weight gain categories within each clinical BMI group.

The optimal gestational weight gain ranges per clinical BMI group were constructed. The odds ratios (ORs) for any adverse outcome were calculated for each gestational weight gain category within the particular clinical BMI group vs all other women within that BMI group. The individual-level data from all cohorts were analyzed simultaneously using multilevel models. The models followed a 2-level hierarchical structure with participants (level1) nested within cohorts (level 2). We used a generalized linear mixed model with a binominal distribution and logit link. A random intercept at the cohort level was included to allow variation in the baseline risk for each cohort. Allowing a random slope for gestational weight gain did not improve the models. Model assumptions regarding linearity, independent errors, and influential values were met. Optimal gestational weight gain was defined as all weight gain categories with a statistically significant protective association $(\mathrm{OR}<1)$ for any adverse outcome. ${ }^{14}$ If a gestational weight gain category with a nonsignificant association was between 2 significant estimates with an OR of less than 1, that category was included in the optimal gestational weight gain range. To construct easily interpretable optimal gestational weight gain ranges directly applicable for clinical practice, the main analyses were not adjusted for maternal age or parity. We also assessed continuous associations of maternal prepregnancy BMI and total gestational weight gain in SDs with any adverse outcome and compared the strength of these associations by using $Z$ tests for the difference in ORs.

The following sensitivity analyses were performed: (1) we redefined the gestational weight gain ranges based on protective associations only $(\mathrm{OR}<1)$ regardless of statistical significance; (2) we adjusted the models for gestational age at birth and excluded preterm births because gestational weight gain depends on length of gestation; (3) we excluded participants with missing data on separate adverse maternal and infant outcomes; (4) we adjusted for maternal age and parity to explore whether optimal gestational weight gain ranges would change when maternal age and parity were taken into account; (5) we excluded cesarean delivery as an adverse outcome and included childhood underweight and overweight as adverse outcomes to explore whether optimal gestational weight gain ranges would change depending on the definition of the composite outcome; and (6) we excluded preeclampsia and gestational diabetes as outcomes to address possible reverse causation. We also constructed optimal gestational weight gain ranges during the first half of pregnancy, which were defined as the difference between weight at median gestational age of 15.4 weeks (quartile 1 and 3,13.2 and 17.1 weeks) and prepregnancy weight using a similar approach.

The clinical performance of the gestational weight gain ranges in this study were assessed as secondary analyses and compared with the NAM guidelines by assessing the number of participants classified as having inadequate or excessive weight gain, the associations with adverse outcomes using binary logistic multilevel models, and the discriminative performance for both classification systems. The discriminative performance of the classification (the ability of the classification to discriminate between those with and those without the outcome) from this study and the NAM guidelines was assessed based on the area under the receiver operating characteristic curve (AUROC). ${ }^{15}$ Predicted probabilities were obtained from binary logistic multilevel models assessing the associations of inadequate and excessive gestational weight gain with the outcomes. The predicted probabilities were used to calculate the AUROC. To assess the associations of the optimal gestational weight gain ranges with clinically relevant outcomes not used for the construction of the ranges, we also assessed low and high birth weight ( $\leq 2500$ g or $\geq 4000$ g). In addition, the clinical performance of both classification systems was assessed in the external validation sample $(n=3505)$.

All statistical tests were 2 -sided with a significance threshold of .05. However, the secondary analyses were not adjusted for multiple testing; therefore, these findings should be considered exploratory. All statistical analyses were performed using SPSS Statistics version 24.0 (IBM) and R version 3.3.3 (R Foundation for Statistical Computing).

\section{Results}

Participant Characteristics in Main Sample

Of the 29 cohorts with the required data ( $n=200175$ participants), 25 were population-based cohorts ( $n=196670$ women) and were included as the main study sample (median age, 30.0 years [quartile 1 and 3, 27.0 and 33.0 years] and 40937 were white). At baseline, 7809 women (4.0\%) were categorized as underweight (BMI <18.5); 133788 (68.0\%), normal weight (BMI, 18.5-24.9); 38828 (19.7\%), overweight (BMI, 25.029.9); 11992 (6.1\%), obesity grade 1 (BMI, 30.0-34.9); 3284 (1.7\%), obesity grade 2 (BMI, 35.0-39.9); and 969 (0.5\%), obesity grade 3 (BMI, $\geq 40.0$ ) (Table). Overall, any adverse outcome occurred in $37.2 \%$ ( $n=73161)$ of women, ranging from $34.7 \%$ (2706 of 7809) among women categorized as underweight to $61.1 \%$ (592 of 969) among women categorized as obesity grade 3 .

Women who gained more gestational weight had a lower maternal prepregnancy BMI and were slightly younger and more often nulliparous than multiparous (eTable 2 in the Supplement). There were no missing data for any individual 


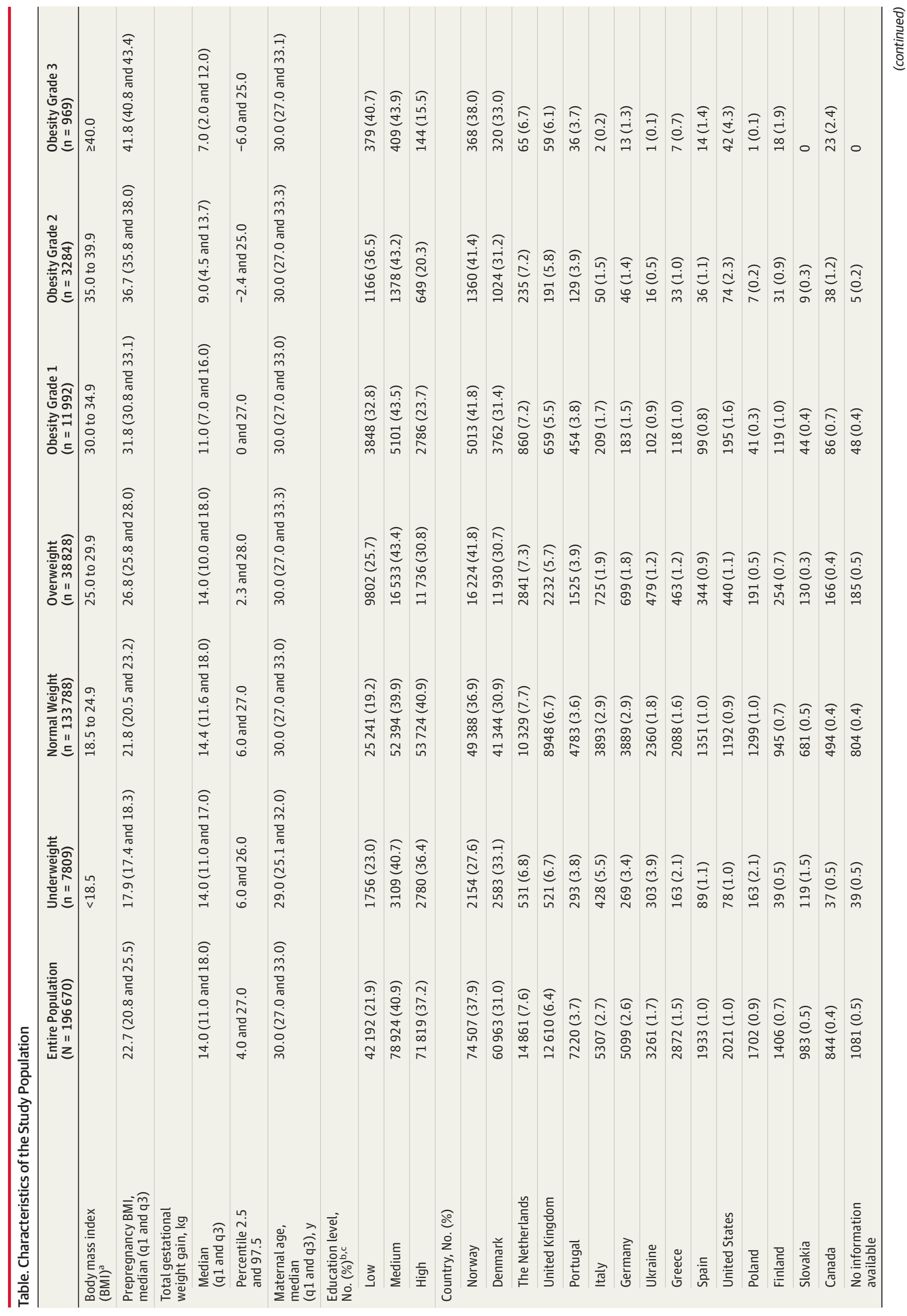




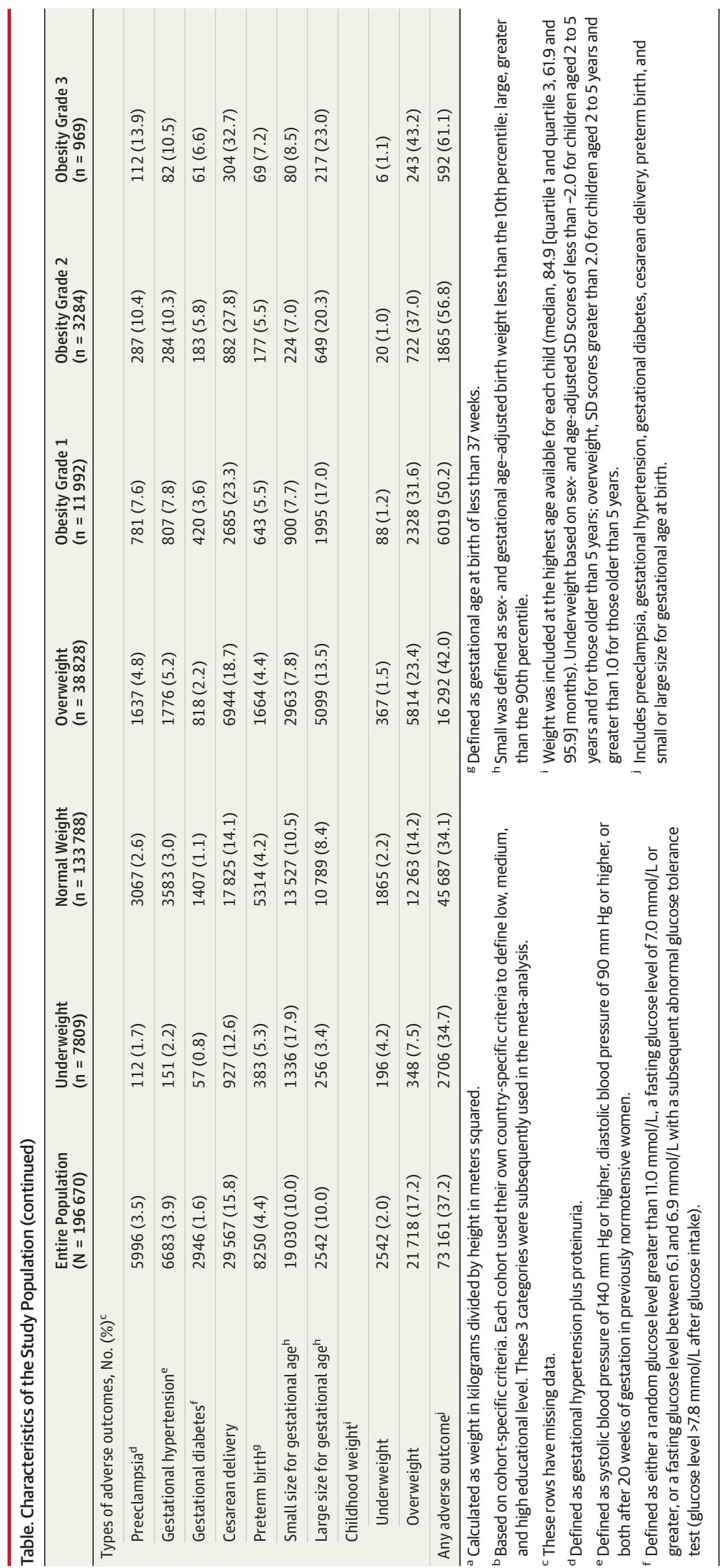




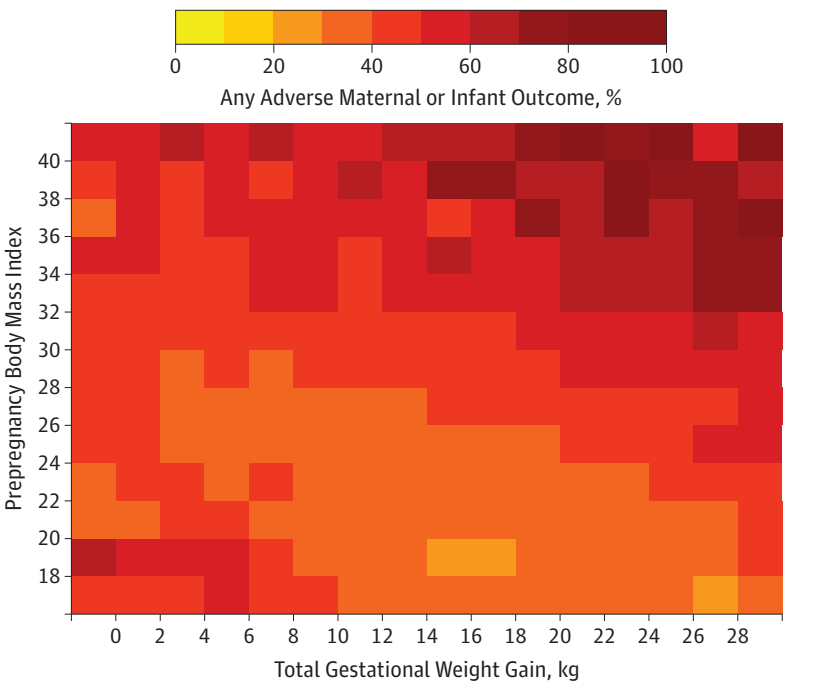

Values represent the absolute risks of any adverse maternal and infant outcome (left panel) and the percentages of participants (right panel) for each combination of body mass index and gestational weight gain. Absolute risk was calculated as No. of participants (any adverse outcome)/No. of participants (body mass index and gestational weight gain category) $\times 100$. The percentages of participants were calculated as the number of participants with each combination of body mass index and gestational weight gain as a percentage of the total study sample. The total study sample size was 196670 . Participants in the extreme categories of prepregnancy body mass index (calculated as weight in kilograms divided by height in meters squared) and gestational weight gain had values beyond the most

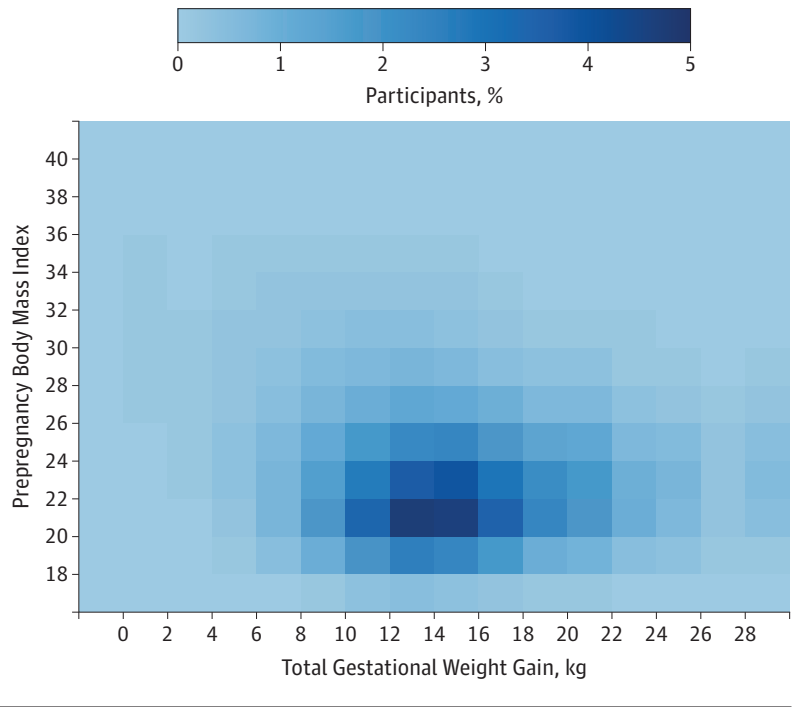

extreme labeled tick marks. Any adverse outcome includes preeclampsia (gestational hypertension plus proteinuria), gestational hypertension (systolic blood pressure $\geq 140 \mathrm{~mm} \mathrm{Hg}$, diastolic blood pressure $\geq 90 \mathrm{~mm} \mathrm{Hg}$, or both after 20 weeks of gestation in previously normotensive women), gestational diabetes (a random glucose level $>11.0 \mathrm{mmol} / \mathrm{L}$, a fasting glucose level $\geq 7.0 \mathrm{mmol} / \mathrm{L}$, or a fasting glucose level between 6.1 and $6.9 \mathrm{mmol} / \mathrm{L}$ with a subsequent abnormal glucose tolerance test [glucose level $>7.8 \mathrm{mmol} / \mathrm{L}$ after glucose intake]), cesarean delivery, preterm birth (gestational age at birth $<37$ weeks), and small or large size for gestational age at birth (sex- and gestational age-adjusted birth weight $<10$ th percentile and $>90$ th percentile, respectively). adverse outcome for 169437 women (86.2\%). Of the remainder, 17093 women (8.7\%) were missing data for gestational hypertensive disorders (including preeclampsia and gestational hypertension), 6898 (3.5\%) for gestational diabetes, 9786 (5.0\%) for cesarean delivery, 8541 (4.3\%) for preterm birth, and 6453 (3.3\%) for size (small or large) for gestational age at birth (eTable 3 in the Supplement). Based on the profiles of all included cohorts, the percentage of women included with multiple singleton pregnancies is about $1 \%$.

\section{Participant Characteristics in Validation Sample}

There were 3505 women included in the validation sample. They had a median age of 31.0 years (quartile 1 and 3, 27.7 and 34.7 years) and 1696 were white. There were 277 women (7.9\%) categorized as underweight; 2400 (68.5\%), normal weight; 577 (16.5\%), overweight; 188 (5.4\%), obesity grade 1; 53 (1.5\%), obesity grade 2 ; and 10 (0.3\%), obesity grade 3 . Any adverse outcome occurred in 1423 women (40.6\%; eTable 4 in the Supplement).

There were no missing data for any individual adverse outcome for 3059 women (87.3\%). Of the remainder, 423 women (12.1\%) were missing data for gestational hypertensive disorders (including preeclampsia and gestational hypertension), 421 (12.0\%) for gestational diabetes, 15 (0.4\%) for cesarean delivery, 426 (12.2\%) for preterm birth, and 7 (0.2\%) for size (small or large) for gestational age at birth (eTable 3 in the Supplement). eTables 5 and 6 in the Supplement provide cohortspecific information for both the main sample and the validation sample.
Maternal Prepregnancy BMI, Gestational Weight Gain, and Absolute Risk for Any Adverse Outcome

The absolute risk for any adverse outcome increased across the full range of maternal prepregnancy BMI and was largely independent of gestational weight gain (Figure 1). The lowest absolute risks were observed among women with low to normal BMI and a moderate to high total gestational weight gain. The lowest risk was $26.7 \%$ (16 of 60) for women with a BMI of less than 18.0 and gestational weight gain of $26.0 \mathrm{~kg}$ to $27.9 \mathrm{~kg}$. The highest absolute risks were observed among women with a high $\mathrm{BMI}$ and a high gestational weight gain. The highest risk was $94.4 \%$ (17 of 18) for women with a BMI of 40.0 or greater and gestational weight gain of $20.0 \mathrm{~kg}$ to $21.9 \mathrm{~kg}$.

Among women categorized as underweight, the absolute risk for any adverse outcome ranged from $29.2 \%$ (387 of 1326) for gestational weight gain of $14.0 \mathrm{~kg}$ to $15.9 \mathrm{~kg}$ to $50.2 \%$ (203 of 404) for gestational weight gain of less than $8.0 \mathrm{~kg}$ (Figure 2). Of all outcomes separately, the absolute risk was highest for small size for gestational age (highest risk: 32.1\% [125 of 390] for gestational weight gain $<8 \mathrm{~kg}$ ).

Among women categorized as normal weight, the absolute risk for any adverse outcome ranged from 31.7\% (7314 of 23073 ) for gestational weight gain of $14.0 \mathrm{~kg}$ to $15.9 \mathrm{~kg}$ to $46.9 \%$ (1256 of 2679) for gestational weight gain of $28.0 \mathrm{~kg}$ or greater and was highest at both extremes of gestational weight gain.

Among women categorized as overweight, the absolute risk for any adverse outcome increased from $37.3 \%$ (249 of 667) for gestational weight gain of $2.0 \mathrm{~kg}$ to $3.9 \mathrm{~kg}$ to $56.4 \%$ (624 of 1107) 

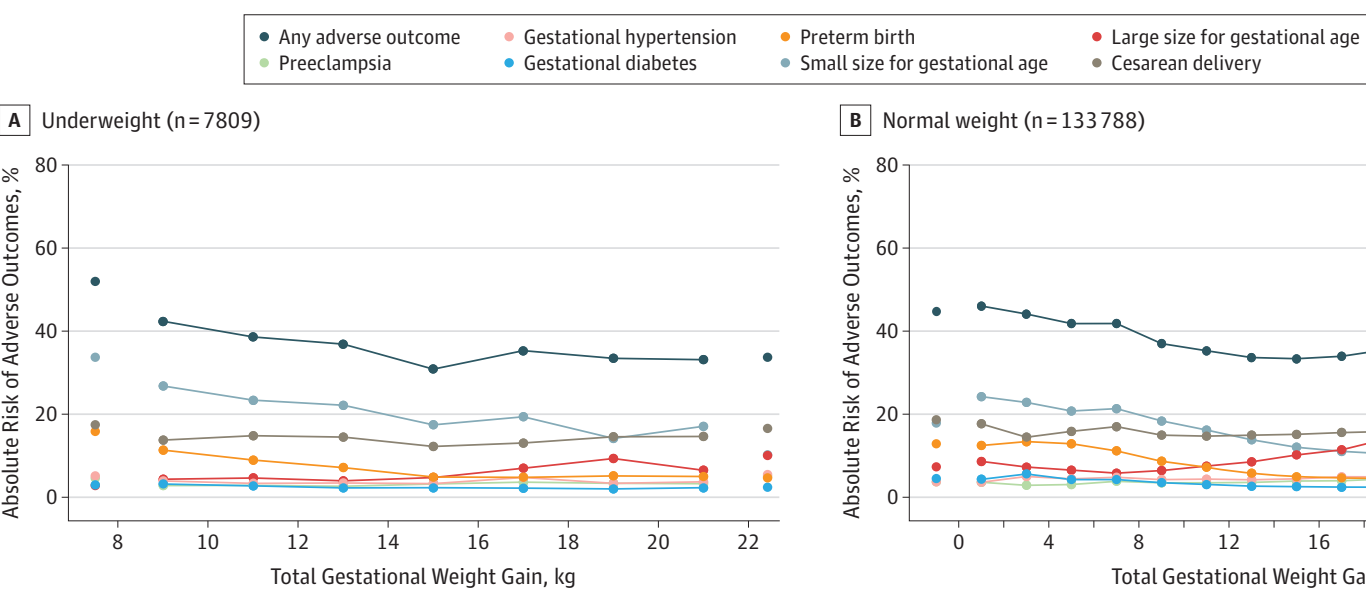

B Normal weight $(n=133788)$

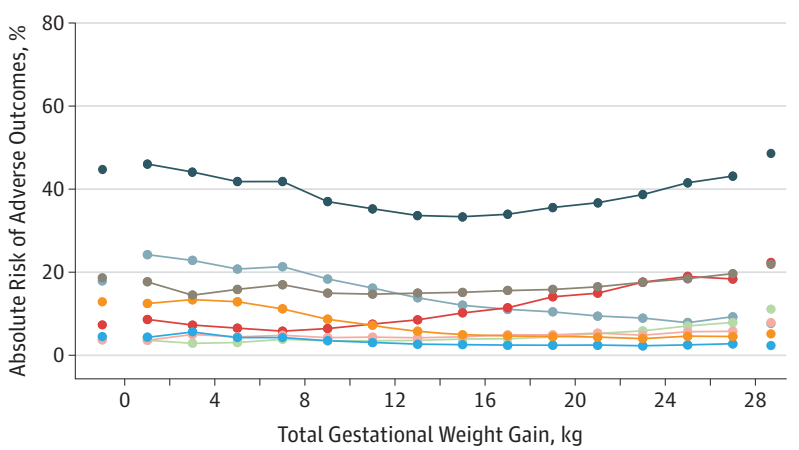

C Overweight $(n=38828)$

D Obesity grade $1(n=11992)$
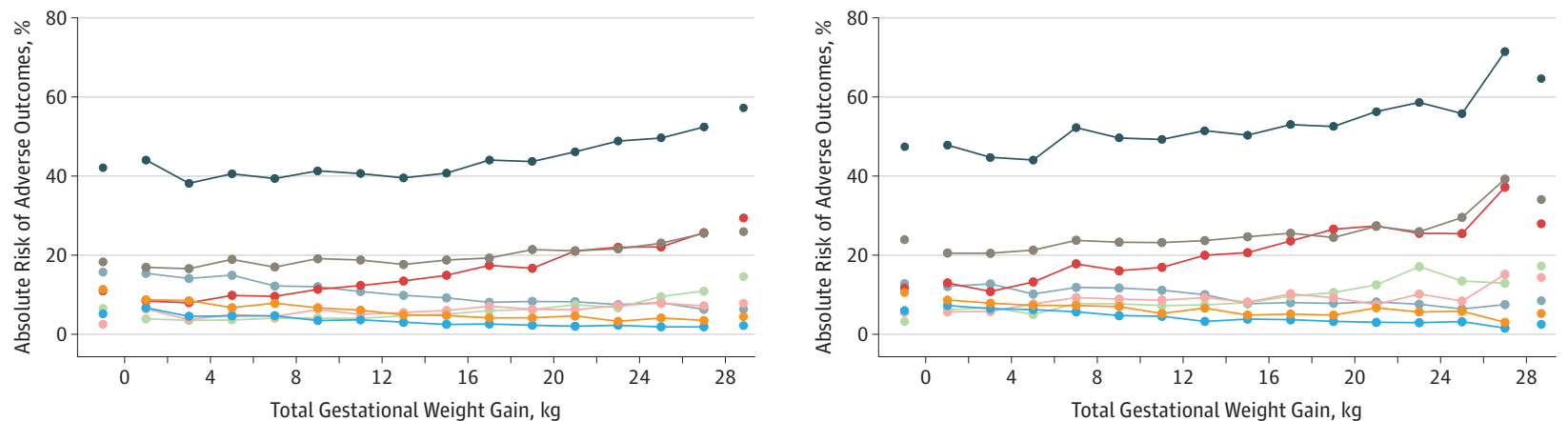

E Obesity grade $2(n=3284)$

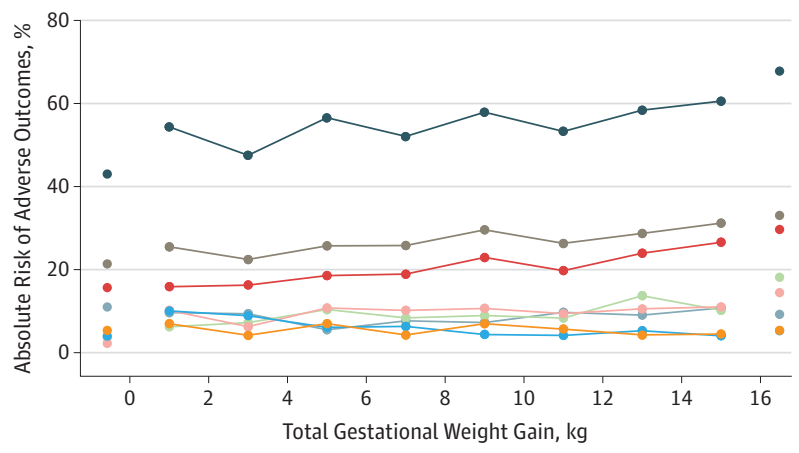

$\mathbf{F}$ Obesity grade $3(n=969)$

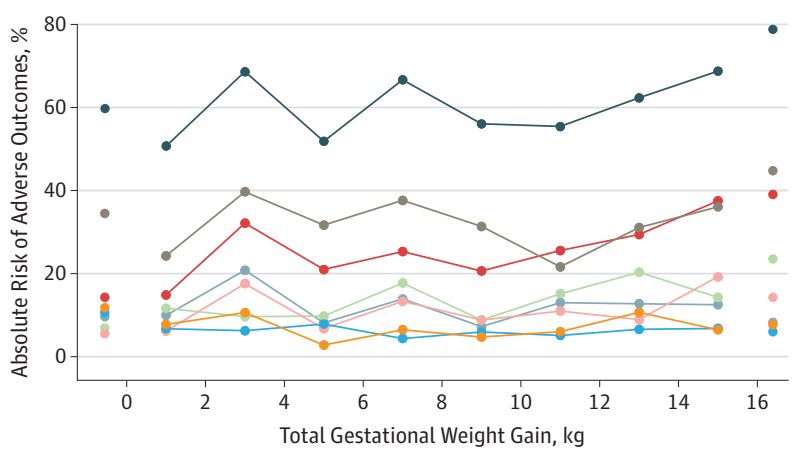

Absolute risk was calculated as (No. of women with adverse outcome/No. of women in gestational weight gain category within body mass index group) $\times 100$. The symbols represent the absolute risk for women in each gestational weight gain category. The gestational weight gain categories were $2 \mathrm{~kg}$ each. Participants in the extreme categories of gestational weight gain had values beyond the most extreme labeled tick marks. The maternal body mass index (calculated as weight in kilograms divided by height in meters squared) categories were underweight (<18.5), normal weight (18.5-24.9), overweight (25.0-29.9), obesity grade 1 (30.0-34.9), obesity grade 2 (35.0-39.9), and obesity grade 3 ( $\geq 40.0)$. Any adverse outcome includes preeclampsia (gestational hypertension plus proteinuria), gestational hypertension (systolic blood pressure $\geq 140 \mathrm{~mm} \mathrm{Hg}$, diastolic blood pressure $\geq 90 \mathrm{~mm} \mathrm{Hg}$, or both after 20 weeks of gestation in

for gestational weight gain of $28.0 \mathrm{~kg}$ or greater. Of all outcomes separately, the absolute risk was highest for cesarean delivery (highest risk: 25.1\% [272 of 1084] for gestational weight gain of $\geq 28.0 \mathrm{~kg}$ ).

previously normotensive women), gestational diabetes (a random glucose level $>11.0 \mathrm{mmol} / \mathrm{L}$, a fasting glucose level $\geq 7.0 \mathrm{mmol} / \mathrm{L}$, or a fasting glucose level between 6.1 and $6.9 \mathrm{mmol} / \mathrm{L}$ with a subsequent abnormal glucose tolerance test [glucose level $>7.8 \mathrm{mmol} / \mathrm{L}$ after glucose intake]), cesarean delivery, preterm birth (gestational age at birth $<37$ weeks), and small or large size for gestational age at birth (sex- and gestational age-adjusted birth weight $<10$ th percentile and $>90$ th percentile, respectively). The odds ratios for the risk of any adverse outcome were $1.28(95 \% \mathrm{Cl}, 1.27-1.29)$ and $1.04(95 \% \mathrm{Cl}, 1.03-1.05)$ per 1-SD increase in maternal prepregnancy body mass index and gestational weight gain, respectively ( $P<.001$ for comparison). The number of cases for each outcome and the total number of participants in each gestational weight gain category appears in eTable 7 in the Supplement.

Among women categorized as obesity grade 1,2 , or 3, the absolute risk for any adverse outcome increased across the range of gestational weight gain. The highest absolute risks were $63.7 \%$ (160 of 251) for gestational weight gain of $28.0 \mathrm{~kg}$ or greater in 
women categorized as obesity grade $1,67.7 \%$ (384 of 567) for gestational weight gain of $16.0 \mathrm{~kg}$ or greater in women categorized as obesity grade 2 , and $78.8 \%$ (93 of 118) for gestational weight gain of $16.0 \mathrm{~kg}$ or greater in women categorized as obesity grade 3 . The association of maternal prepregnancy BMI with the risk for any adverse outcomes was stronger than the association of gestational weight gain. The ORs for the risk of any adverse outcome were 1.28 (95\% CI, 1.27-1.29) and 1.04 (95\% CI, 1.03-1.05) per 1-SD increase in maternal prepregnancy BMI and gestational weight gain, respectively ( $P<.001$ for comparison). The absolute data for each gestational weight gain category appear in eTable 7 in the Supplement.

Optimal Gestational Weight Gain per Clinical BMI Group The optimal gestational weight gain ranges associated with the lowest risks for any adverse outcome appear in Figure 3. Among women categorized as underweight, the optimal gestational weight gain range was $14.0 \mathrm{~kg}$ to less than $16.0 \mathrm{~kg}$, with corresponding OR and absolute risk reduction (ARR; the percentage reduction in absolute risk of any adverse outcome) of 0.74 (95\% CI, 0.65-0.84) and 0.07\% (95\% CI, 0.04\%-0.09\%), respectively. Among women categorized as normal weight, the optimal gestational weight gain range was $10.0 \mathrm{~kg}$ to less than $18.0 \mathrm{~kg}$ (ORs at the outer ends of this range, 0.96 [95\% CI, 0.930.99] and 0.91 [95\% CI, 0.88-0.95]; ARRs, 0.01\% [95\% CI, 0\%$0.01 \%$ ] and $0.02 \%$ [95\% CI, 0.01\%-0.03\%]). Among women categorized as overweight, the optimal gestational weight gain range was $2.0 \mathrm{~kg}$ to less than $16.0 \mathrm{~kg}$ (ORs at the outer ends of this range, 0.81 [95\% CI, 0.69-0.95] and 0.90 [95\% CI, 0.850.96]; ARRs, 0.05\% [95\% CI, 0.01\%-0.08\%] and 0.02\% [95\% CI, 0.01\%-0.04\%]). Among women categorized as obesity grade 1 , the optimal gestational weight gain range was $2.0 \mathrm{~kg}$ to less than $6.0 \mathrm{~kg}$ (ORs at the outer ends of this range, 0.76 [95\% CI, 0.64-0.91] and 0.73 [95\% CI, 0.64-0.84]; ARRs, 0.07\% [95\% CI, 0.02\%-0.11\%] and 0.08\% [95\% CI, 0.04\%-0.11\%]). Among women categorized as obesity grade 2, the optimal gestational weight gain range was weight loss or gain of $0 \mathrm{~kg}$ to less than $4.0 \mathrm{~kg}$ (median weight loss: $3.0 \mathrm{~kg}$; ORs at the outer ends of this range, 0.55 [95\% CI, 0.39-0.78] and 0.67 [95\% CI, 0.51-0.88]; ARRs, 0.14\% [95\% CI, 0.06\%-0.22\%] and 0.10\% [95\% CI, 0.03\%-0.17\%]). Among women categorized as obesity grade 3 , the optimal gestational weight gain range was $0 \mathrm{~kg}$ to less than $6.0 \mathrm{~kg}$ (ORs for the outer ends of this range, 0.59 [95\% CI, 0.41-0.85] and 0.62 [95\% CI, 0.41-0.94]; ARRs, 0.12\% [95\% CI, 0.03\%-0.21\%] and 0.10\% [95\% CI, 0\%-0.20\%]). The ORs and ARRs for each gestational weight gain category used to determine the optimal ranges appear in eTable 8 and eTable 9 in the Supplement, respectively.

The gestational weight gain ranges defined in this study and the NAM ranges appear in eTable 10 in the Supplement. The gestational weight gain ranges in this study were roughly comparable with the NAM ranges for underweight, normal weight, and overweight, and were lower for all obesity grades. This study classified $11.3 \%$ of women ( $n=22236$ ) in the main sample as having inadequate gestational weight gain and $33.8 \%$ of women ( $n=66463$ ) as having excessive gestational weight gain. The NAM categories classified $21.5 \%$ of women ( $n=42323$ ) as having inadequate gestational weight gain and $42.0 \%$ of women
( $\mathrm{n}=82544)$ as having excessive gestational weight gain. Gestational weight gain outside the ranges from the current study and the NAM ranges was associated with adverse outcomes (eFigure 2 and eFigure 3 in the Supplement). Each classification system had a low to moderate ability to distinguish between those with and those without adverse outcomes (range for AUROC, 0.55-0.77; eFigure 4 in the Supplement).

\section{Sensitivity Analyses}

The sensitivity analyses, in which optimal gestational weight gain was determined based on protective associations regardless of statistical significance, resulted in broader ranges of optimal gestational weight gain (eFigure 5 in the Supplement). Optimal gestational weight gain ranges similar to those from the main analyses were observed when length of gestation was considered and when participants with missing individual outcome data were excluded (eTable 11 in the Supplement). In addition, the sensitivity analyses showed that optimal weight gain definitions were not altered by including or excluding preterm birth, cesarean delivery, childhood underweight or overweight, gestational diabetes, and preeclampsia as adverse outcomes or by adjusting for maternal age and parity (eTable 11 in the Supplement).

Of all the women classified as having excessive gestational weight gain during the full pregnancy, $84.6 \%$ also would be classified as having excessive weight gain during the first half of the pregnancy (eFigure 6, eTable 12, and eTable 13 in the Supplement). Results for the validation sample showed that the discriminative performance of the optimal gestational weight gain ranges developed in this study and the weight gain ranges from the NAM guidelines were consistent with findings in the main study sample (range for AUROC, 0.50-0.79; eTable 14, eFigure 7, and eFigure 8 in the Supplement).

\section{Discussion}

Maternal prepregnancy BMI, and to a lesser extent gestational weight gain, are associated with risks of adverse maternal and infant adverse outcomes. Gestational weight gain ranges that were associated with lower risks for adverse outcomes were $14.0 \mathrm{~kg}$ to less than $16.0 \mathrm{~kg}$ for women categorized as being underweight; $10.0 \mathrm{~kg}$ to less than $18.0 \mathrm{~kg}$ for normal weight; $2.0 \mathrm{~kg}$ to less than $16.0 \mathrm{~kg}$ for overweight; $2.0 \mathrm{~kg}$ to less than $6.0 \mathrm{~kg}$ for obesity grade 1 ; weight loss or gain of $0 \mathrm{~kg}$ to less than $4.0 \mathrm{~kg}$ for obesity grade 2 ; and weight gain of $0 \mathrm{~kg}$ to less than $6.0 \mathrm{~kg}$ for obesity grade 3 .

Gestational weight gain outside these ranges was associated with adverse outcomes. However, discriminative performance of gestational weight gain with adverse maternal and infant outcomes was low to moderate. Prepregnancy BMI was more strongly associated with adverse maternal and infant outcomes than the amount of gestational weight gain.

Prepregnancy BMI is significantly associated with pregnancy complications and offspring obesity and also is associated with gestational weight gain. ${ }^{5,6}$ Results from this study suggest that maternal prepregnancy BMI was more strongly associated with adverse maternal and infant outcomes than gestational weight gain. Therefore, prepregnancy BMI may be an important focus for preconception counseling. 


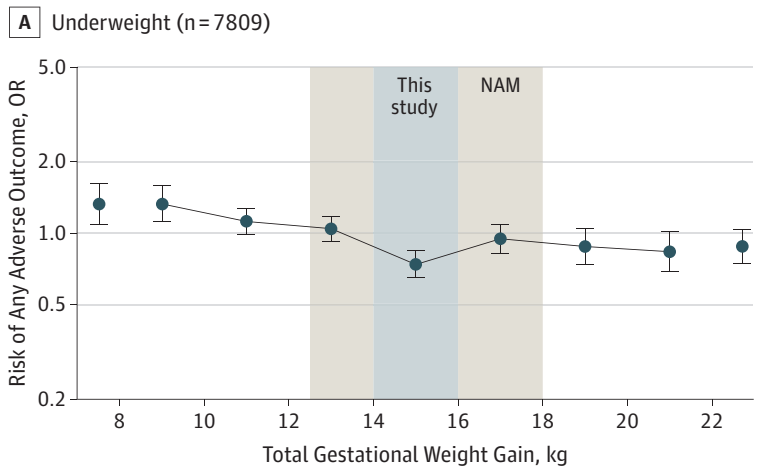

C Overweight $(n=38828)$

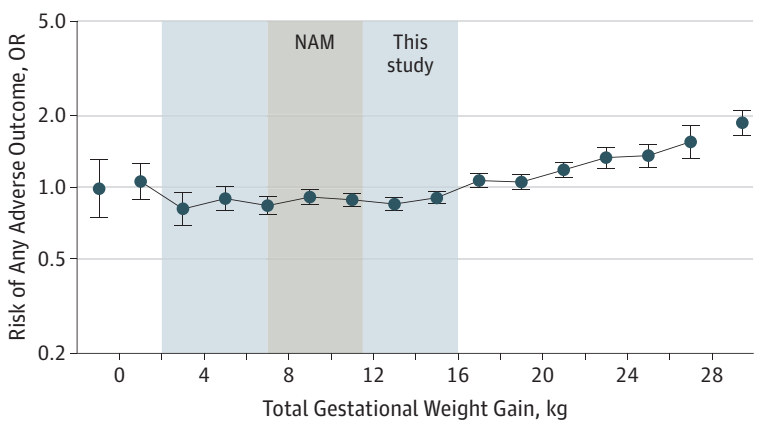

E Obesity grade $2(n=3284)$

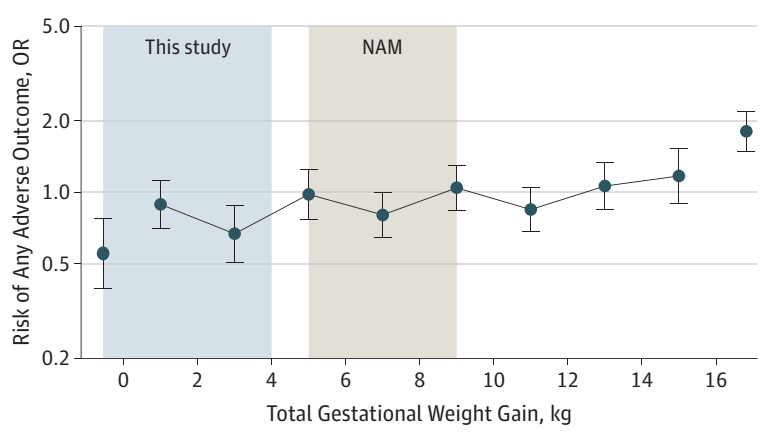

OR indicates odds ratio and it reflects the risk for any adverse outcome per gestational weight gain category for women with underweight, normal weight, overweight, obesity grade 1 , obesity grade 2 , and obesity grade 3 , parts A-F, respectively, compared with all other gestational weight gain categories in that specific group for clinical maternal body mass index (BMl; calculated as weight in kilograms divided by height in meters squared). The solid circles represent the OR for all participants in each gestational weight gain category. The error bars indicate $95 \% \mathrm{Cls}$. The blue area represents the optimal gestational weight gain range according to the current analysis, the gray area represents the gestational weight gain ranges recommended by the US National Academy of Medicine (NAM; formerly the Institute of Medicine). The gestational weight gain categories were $2 \mathrm{~kg}$ each. Participants in the extreme categories of gestational weight gain had values beyond the most extreme labeled tick marks. The maternal BMI categories were underweight (<18.5), normal weight (18.5-24.9), overweight (25.0-29.9), obesity grade 1 (30.0-34.9), obesity grade 2 (35.0-39.9), and obesity grade 3 ( $\geq 40.0$ ). Any adverse outcome includes preeclampsia (gestational hypertension plus proteinuria), gestational hypertension (systolic blood pressure
B Normal weight $(\mathrm{n}=133788)$

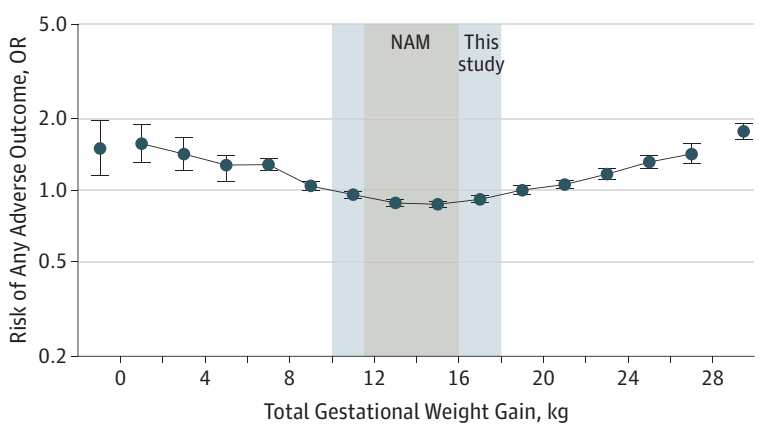

D Obesity grade $1(n=11992)$

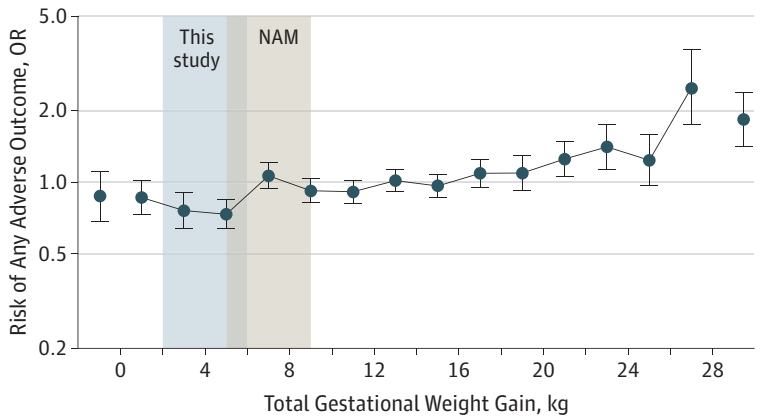

F Obesity grade $3(n=969)$

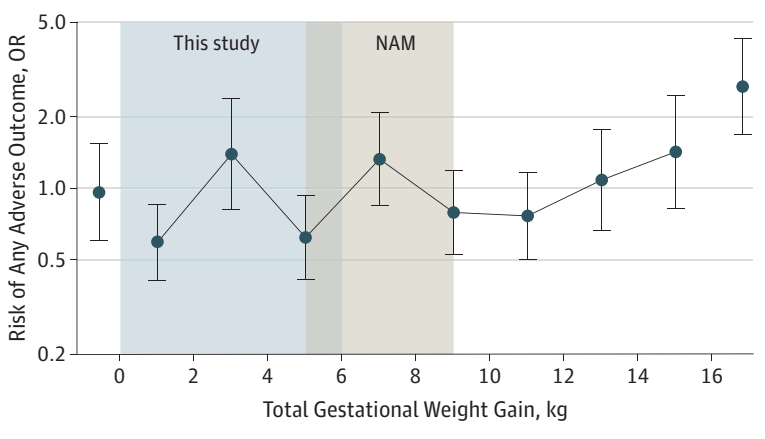

$\geq 140 \mathrm{~mm} \mathrm{Hg}$, diastolic blood pressure $\geq 90 \mathrm{~mm} \mathrm{Hg}$, or both after 20 weeks of gestation in previously normotensive women), gestational diabetes (a random glucose level $>11.0 \mathrm{mmol} / \mathrm{L}$, a fasting glucose level $\geq 7.0 \mathrm{mmol} / \mathrm{L}$, or a fasting glucose level between 6.1 and $6.9 \mathrm{mmol} / \mathrm{L}$ with a subsequent abnormal glucose tolerance test [glucose level $>7.8 \mathrm{mmol} / \mathrm{L}$ after glucose intake]), cesarean delivery, preterm birth (gestational age at birth $<37$ weeks), and small or large size for gestational age at birth (sex- and gestational age-adjusted birth weight $<10$ th percentile and $>90$ th percentile, respectively). For the gestational weight gain ranges defined in this study, a statistically significant OR lower than 1 for a gestational weight gain category was considered the optimal weight gain. If a nonsignificant association (either with an $O R>1,<1$, or of 1 ) for a gestational weight gain category was surrounded by 2 significant estimates with an OR below 1 , that gestational weight gain category was included in the optimal gestational weight gain range. The number of cases for each outcome and the total number of participants in each gestational weight gain category appear in eTable 7 in the Supplement. The optimal gestational weight gain ranges based only on protective associations appear in eFigure 5 in the Supplement.
Previous studies that attempted to define optimal gestational weight gain associated with fewer adverse outcomes differed considerably among study populations, statistical approaches, outcomes, and conclusions regarding optimal gestational weight gain ranges. ${ }^{14,16-22}$ Only 1 study of 120251 obese US women defined optimal gestational weight gain ranges 
according to maternal obesity grade $1(4.5 \mathrm{~kg}-11.3 \mathrm{~kg})$, obesity grade $2(0 \mathrm{~kg}-4.1 \mathrm{~kg}$ ), and obesity grade 3 (weight loss $<4 \mathrm{~kg}$ ), and that study used data from term births only. ${ }^{21}$

Compared with prior work, the present study focused on common and important adverse maternal and infant outcomes, included women from multiple Western countries, and compared the associations of gestational weight gain and prepregnancy BMI with adverse outcomes. Consistent with the NAM guidelines, this study used total gestational weight gain to identify optimal gestational weight gain ranges instead of gestational weight gain per week because gestational weight gain does not have a linear pattern. ${ }^{7,8}$ Total gestational weight gain is dependent in part on pregnancy duration. The observed results were similar after adjustment for gestational age at birth and after excluding preterm births. Consistent with the NAM guidelines, this study showed that among women with higher prepregnancy BMI, lower gestational weight gain was associated with fewer adverse outcomes. Gestational weight gain ranges for women categorized as obesity grade 1, 2, or 3 were lower than the NAM guidelines and even involved weight loss for severely obese women, although neither classification was predictive for adverse outcomes. However, the results for severely obese women should be interpreted with caution because the optimal gestational weight gain ranges for obesity grades 1 through 3 associated with better outcomes fluctuate and do not follow a clear linear trend. These results may represent the relatively small sample size of obese women and lack of statistical power rather than biological plausibility. Future studies should evaluate the effect and safety of weight loss during pregnancy in severely obese women.

Gestational weight gain guidelines are used in several Western countries for preconception counseling. The gestational weight gain ranges developed in this study classified fewer women as having suboptimal weight gain compared with the NAM guidelines. However, the discriminative performance, as indicated by the AUROC, was weak for both classification systems. This suggests that the use of gestational weight gain guidelines may need to be reconsidered for individual prediction of the risk for adverse outcomes. Future research should assess whether optimal gestational weight gain ranges combined with other maternal and fetal pregnancy characteristics are useful for prediction of adverse outcomes.

The findings from this study suggest that prepregnancy weight might be a more important target for interventions than gestational weight gain. Previous studies of dietary and physical activity interventions for pregnant women have not shown an effect on pregnancy outcomes. ${ }^{23-26}$ Based on current evidence, future clinical trials designed to reduce weight-related maternal and infant adverse outcomes should focus on maternal weight before or at the start of pregnancy.

\section{Limitations}

This study has several limitations. First, not all invited cohorts were able to participate in the current analyses. Second, the analyses did not measure changes in the association of gestational weight gain with adverse outcomes over time. The results may be biased if the association of gestational weight gain with adverse outcomes changed over time. Third, data on prepregnancy weight was mainly self-reported, and the latest weight during pregnancy was either self-reported or measured. This may have led to misclassification of gestational weight gain. Fourth, the composite outcome of any adverse outcome might have been misclassified as a result of some missing data for individual outcomes. Fifth, all outcomes were considered equally important and the analyses did not account for the differences in outcome severity. Sixth, cesarean delivery may be due to many factors and may not be an appropriate outcome for studying associations of weight change with adverse maternal outcomes. ${ }^{7}$ Seventh, information on stillbirth was not available. Eighth, optimal gestational weight gain was defined as a protective association with the risk for any adverse outcome, reflecting the best outcome possible and limiting the number of participants incorrectly classified as having adequate gestational weight gain. The ranges would be slightly broader if optimal gestational weight gain was defined as no increased risk for adverse outcomes, which includes both a protective association and a null association. Ninth, the analyses were not adjusted for multiple testing. Tenth, as a result of the limited sample sizes for underweight and severely obese women, heterogeneity was not assessed. Eleventh, based on the profiles of all the included cohorts, about $1 \%$ of women were included more than once for multiple pregnancies. Twelfth, for some outcomes, discriminative performance in the validation sample was lower than in the main sample, potentially resulting from overfitting of the models in the main sample.

\section{Conclusions}

In this meta-analysis of pooled individual participant data from 25 cohort studies, the risk for adverse maternal and infant outcomes varied by gestational weight gain and across the range of prepregnancy weights. The estimates of optimal gestational weight gain may inform prenatal counseling; however, the optimal gestational weight gain ranges had limited predictive value for the outcomes assessed.

\section{ARTICLE INFORMATION}

Accepted for Publication: March 29, 2019

LifeCycle Project-Maternal Obesity and Childhood Outcomes Authors: The following investigators take authorship responsibility for the study results: Ellis Voerman, MSc; Susana Santos, PhD; Hazel Inskip, MSc, PhD; Pilar Amiano, PharmD, MSc; Henrique Barros, MD, PhD; Marie-Aline Charles, MD, MPH; Leda Chatzi, MD, PhD; George P. Chrousos, MD, ScD; Eva Corpeleijn, PhD; Sarah Crozier, PhD; Myriam Doyon, MSc; Merete Eggesbø, MD, PhD;
Maria Pia Fantini, MD; Sara Farchi, MSc; Francesco Forastiere, MD, PhD; Vagelis Georgiu, MSc; Davide Gori, MD, PhD; Wojciech Hanke, PhD; Irva Hertz-Picciotto, PhD; Barbara Heude, PhD; Marie-France Hivert, MD; Daniel Hryhorczuk, MD, MPH; Carmen Iñiguez, PhD; Anne M. Karvonen, PhD; Leanne K. Küpers, PhD; Hanna Lagström, PhD; Debbie A. Lawlor, PhD; Irina Lehmann, PhD; Per Magnus, MD, PhD; Renata Majewska, MSc; Johanna Mäkelä, PhD; Yannis Manios, PhD, MMedSc; Monique Mommers, PhD; Camilla S. Morgen, MSc, PhD; George Moschonis, PhD; Ellen A. Nohr, PhD;
Anne-Marie Nybo Andersen, MD, PhD; Emily Oken, MD, MPH; Agnieszka Pac, MSc, PhD; Eleni Papadopoulou, PhD; Juha Pekkanen, MD, PhD; Costanza Pizzi, PhD; Kinga Polanska, PhD; Daniela Porta, MSc; Lorenzo Richiardi, MD, PhD; Sheryl L. Rifas-Shiman, MPH; Nel Roeleveld, PhD, MSc; Luca Ronfani, MD, PhD; Ana C. Santos, PhD; Marie Standl, $\mathrm{PhD}$; Hein Stigum, PhD; Camilla Stoltenberg, MD, PhD; Elisabeth Thiering, PhD; Carel Thijs, MD, PhD; Maties Torrent, MD, PhD; Tomas Trnovec, MD, PhD; Marleen M. H. J. van Gelder, PhD; Lenie van Rossem, PhD; Andrea von Berg, MD; Martine Vrijheid, PhD; Alet 
Wijga, PhD; Oleksandr Zvinchuk, MS; Thorkild I. A. Sørensen, MD, Dr Med Sci; Keith Godfrey, BM, PhD; Vincent W. V. Jaddoe, MD, PhD; Romy Gaillard, MD, PhD.

Affiliations of LifeCycle Project-Maternal Obesity and Childhood Outcomes Authors: Generation R Study Group, Erasmus MC, University Medical Center, Rotterdam, the Netherlands (Voerman, S. Santos, Jaddoe, Gaillard); Department of Pediatrics, Erasmus MC, University Medical Center, Rotterdam, the Netherlands (Voerman, S. Santos, Jaddoe, Gaillard); MRC Lifecourse Epidemiology Unit, University of Southampton, Southampton, England (Inskip, Crozier, Godfrey); NIHR Southampton Biomedical Research Centre, University of Southampton and University Hospital Southampton NHS Foundation Trust, Southampton, England (Inskip, Godfrey); Public Health Division of Gipuzkoa, San Sebastián, Spain (Amiano); BioDonostia Research Institute, San Sebastián, Spain (Amiano); CIBER Epidemiología y Salud Pública, Madrid, Spain (Amiano, Iñiguez, Vrijheid); EPI Unit-Instituto de Saúde Pública, Universidade do Porto, Porto, Portugal (Barros, A. C. Santos); Department of Public Health and Forensic Sciences and Medical Education, Unit of Clinical Epidemiology, Predictive Medicine and Public Health, University of Porto Medical School, Porto, Portugal (Barros, A. C. Santos); INSERM, UMR1153 Epidemiology and Biostatistics Sorbonne Paris Cité Center, ORCHAD Team, Villejuif, France (Charles, Heude); Paris Descartes University, Villejuif, France (Charles, Heude); Department of Preventive Medicine, Keck School of Medicine, University of Southern California, Los Angeles (Chatzi); Department of Social Medicine, Faculty of Medicine, University of Crete, Heraklion, Greece (Chatzi, Georgiu); Department of Genetics and Cell Biology, Maastricht University, Maastricht, the Netherlands (Chatzi); First Department of Pediatrics, National and Kapodistrian University of Athens, Medical School, Aghia Sophia Children's Hospital, Athens, Greece (Chrousos); University of Groningen, University Medical Center Groningen, Department of Epidemiology, Groningen, the Netherlands (Corpeleijn, Küpers); Centre de Recherche du Centre Hospitalier de I'Universite de Sherbrooke, Sherbrooke, Quebec, Canada (Doyon, Hivert); Department of Exposure and Environmental Epidemiology, Norwegian Institute of Public Health, Oslo, Norway (Eggesbø); Department of Biomedical and Neuromotor Sciences, University of Bologna, Bologna, Italy (Fantini, Gori); Department of Epidemiology, Lazio Regional Health Service, Rome, Italy (Farchi, Forastiere, Porta); Department of Environmental Epidemiology, Nofer Institute of Occupational Medicine, Lodz, Poland (Hanke, Polanska); Department of Public Health Sciences, School of Medicine, University of California, Davis (Hertz-Picciotto); Department of Population Medicine, Harvard Medical School, Harvard Pilgrim Health Care Institute, Boston, Massachusetts (Hivert, Oken, Rifas-Shiman); Diabetes Unit, Massachusetts General Hospital, Boston (Hivert); Center for Global Health, College of Medicine, University of Illinois, Chicago (Hryhorczuk); Department of Statistics and Computational Research, Universitat de València, València, Spain (Iñiguez); Department of Health Security, National Institute for Health and Welfare, Kuopio, Finland (Karvonen, Pekkanen); Division of Human Nutrition and Health, Wageningen University and Research, Wageningen, the Netherlands (Küpers); MRC
Integrative Epidemiology Unit, University of Bristol, Bristol, England (Küpers, Lawlor); Population Health Science, Bristol Medical School, University of Bristol, Bristol, England (Küpers, Lawlor); Department of Public Health, University of Turku, Turku, Finland (Lagström); Department of Environmental Immunology/Core Facility Studies, Helmholtz Centre for Environmental ResearchUFZ, Leipzig, Germany (Lehmann); Division of Health Data and Digitalization, Norwegian Institute of Public Health, Oslo, Norway (Magnus); Department of Epidemiology, Jagiellonian University Medical College, Krakow, Poland (Majewska, Pac); Turku Centre for Biotechnology, University of Turku and Abo Akademi University, Turku, Finland (Mäkelä); Department of Nutrition and Dietetics, School of Health Science and Education, Harokopio University, Athens, Greece (Manios); Department of Epidemiology, Care and Public Health Research Institute, Maastricht University, Maastricht, the Netherlands (Mommers, Thijs); National Institute of Public Health, University of Southern Denmark, Copenhagen (Morgen); Department of Public Health, Section of Epidemiology, University of Copenhagen, Copenhagen, Denmark (Morgen, Nybo Andersen, Sørensen); Department of Dietetics, Nutrition, and Sport, La Trobe University, Melbourne, Australia (Moschonis); Research Unit for Gynaecology and Obstetrics, Institute for Clinical Research, University of Southern Denmark, Odense (Nohr); Department of Environmental Exposures and Epidemiology, Domain of Infection Control and Environmental Health, Norwegian Institute of Public Health, Oslo, Norway (Papadopoulou); Department of Public Health, University of Helsinki, Helsinki, Finland (Pekkanen); Department of Medical Sciences, University of Turin, Turin, Italy (Pizzi, Richiardi); Department for Health Evidence, Radboud Institute for Health Sciences, Radboud University Medical Center, Nijmegen, the Netherlands (Roeleveld, van Gelder); Institute for Maternal and Child Health-IRCCS Burlo Garofolo, Trieste, Italy (Ronfani); Institute of Epidemiology, Helmholtz Zentrum München-German Research Center for Environmental Health, Neuherberg, Germany (Standl, Thiering); Department of Noncommunicable Diseases, Norwegian Institute of Public Health, Oslo, Norway (Stigum); Norwegian Institute of Public Health, Oslo, Norway (Stoltenberg); Department of Global Public Health and Primary Care, University of Bergen, Bergen, Norway (Stoltenberg); Dr von Hauner Children's Hospital, Ludwig-Maximilians-University Munich, Munich, Germany (Thiering); Ib-Salut, Area de Salut de Menorca, Palma, Spain (Torrent); Department of Environmental Medicine, Slovak Medical University, Bratislava, Slovakia (Trnovec); Radboud Reshape Innovation Center, Radboud University Medical Center, Nijmegen, the Netherlands (van Gelder); Julius Center for Health Sciences and Primary Care, University Medical Center Utrecht, Utrecht University, Utrecht, the Netherlands (van Rossem); Research Institute, Department of Pediatrics, Marien-Hospital Wesel, Wesel, Germany (von Berg); ISGlobal, Institute for Global Health, Barcelona, Spain (Vrijheid); Universitat Pompeu Fabra, Barcelona, Spain (Vrijheid); National Institute for Public Health and the Environment, Bilthoven, the Netherlands (Wijga); Department of Medical and Social Problems of Family Health, Institute of Pediatrics, Obstetrics and Gynecology, Kyiv, Ukraine (Zvinchuk); Novo Nordisk Foundation Center for
Basic Metabolic Research, Section of Metabolic Genetics, Faculty of Health and Medical Sciences, University of Copenhagen, Copenhagen, Denmark (Sørensen); Department of Epidemiology, Erasmus MC, University Medical Center, Rotterdam, the Netherlands (Jaddoe)

Author Contributions: Ms Voerman and Dr Gaillard had full access to all of the data in the study and take responsibility for the integrity of the data and the accuracy of the data analysis. Drs Jaddoe and Gaillard contributed equally to this work. Concept and design: Voerman, S. Santos, Barros, Doyon, Hivert, Hryhorczuk, Lawlor, Mäkelä, Manios, Moschonis, Thijs, Godfrey, Jaddoe, Gaillard. Acquisition, analysis, or interpretation of data: Voerman, S. Santos, Inskip, Amiano, Barros, Charles, Chatzi, Chrousos, Corpeleijn, Crozier, Eggesbø, Fantini, Farchi, Forastiere, Georgiu, Gori, Hanke, Hertz-Picciotto, Heude, Hryhorczuk, Iñiguez, Karvonen, Küpers, Lagström, Lawlor, Lehmann, Magnus, Majewska, Manios, Mommers, Morgen, Moschonis, Nohr, Nybo Andersen, Oken, Pac, Papadopoulou, Pekkanen, Pizzi, Polanska, Porta, Richiardi, Rifas-Shiman, Roeleveld, Ronfani, A. Santos, Standl, Stigum, Stoltenberg, Thiering, Thijs, Torrent, Trnovec, van Gelder, van Rossem, Vrijheid, Wijga, Zvinchuk, Sørensen, Godfrey، Jaddoe, Gaillard.

Drafting of the manuscript: Voerman, S. Santos, Jaddoe, Gaillard.

Critical revision of the manuscript for important intellectual content: Inskip, Amiano, Barros, Charles, Chatzi, Chrousos, Corpeleijn, Crozier, Doyon, Eggesbø, Fantini, Farchi, Forastiere, Georgiu, Gori, Hanke, Hertz-Picciotto, Heude, Hivert, Hryhorczuk, Iñiguez, Karvonen, Küpers, Lagström, Lawlor, Lehmann, Magnus, Majewska, Mäkelä, Manios, Mommers, Morgen, Moschonis, Nohr, Nybo Andersen, Oken, Pac, Papadopoulou, Pekkanen, Pizzi, Polanska, Porta, Richiardi, Rifas-Shiman, Roeleveld, Ronfani, A. Santos, Standl, Stigum, Stoltenberg, Thiering, Thijs, Torrent, Trnovec, van Gelder, van Rossem, Vrijheid, Wijga, Zvinchuk, Sørensen, Godfrey, Jaddoe.

Statistical analysis: Voerman, Inskip, Georgiu, Hryhorczuk, Stigum, Gaillard.

Obtained funding: Inskip, Barros, Corpeleijn, Hanke, Hertz-Picciotto, Karvonen, Lawlor, Nybo Andersen, Oken, Pekkanen, Polanska, A. Santos, Thijs, Torrent, Godfrey, Jaddoe.

Administrative, technical, or material support: Barros, Corpeleijn, Doyon, Fantini, Farchi, Iñiguez, Karvonen, Küpers, Lagström, Lehmann, Magnus, Mäkelä, Manios, Morgen, Moschonis, Nohr, Nybo Andersen, Oken, Papadopoulou, Pekkanen, Pizzi, Rifas-Shiman, Stoltenberg, Thijs, Torrent, van Gelder, van Rossem, Wijga, Zvinchuk, Jaddoe. Supervision: Amiano, Barros, Charles, Chatzi, Forastiere, Hivert, Manios, Moschonis, Roeleveld Torrent, Vrijheid, Jaddoe, Gaillard.

\section{Conflict of Interest Disclosures: Dr Godfrey} reported receiving speakers fees from companies selling nutritional products; and being part of an academic consortium that has received research funding from Abbott Nutrition, Nestec, and Danone. Dr Lawlor reported receiving support from Roche Diagnostics and Medtronic for biomarker research. No other disclosures were reported.

Funding/Support: Avon Longitudinal Study of Parents and Children (ALSPAC): Funded by grant 102215/2/13/2 from the UK Medical Research Council and Wellcome, core support from the University of 
Bristol, grant R01 DK10324 from the US National Institutes of Health, grant agreement 669545 from the European Research Council under the European Union's Seventh Framework Programme (FP7/ 2007-2013), award MC_UU_12013/5 from the UK Medical Research Council, and Dr Lawlor is a National Institute for Health Research senior investigator (NF-SI-0611-10196). Cohort of Newborns in Emilia Romagna (CONER): No funding reported. Danish National Birth Cohort (DNBC): The Danish Epidemiology Science Centre initiated and created the DNBC and this center was established by the Danish National Research Foundation via a major grant. Additional support was obtained from the Pharmacy Foundation, the Egmont Foundation, the March of Dimes Birth Defects Foundation, the Augustinus Foundation, and the Health Foundation. The 7-year follow-up study was supported by award 195/04 from the Lundbeck Foundation and award SSVF 0646 from the Danish Medical Research Council. Étude des Déterminants pré et postnatals du développement et de la santé de l'ENfant (EDEN): Supported by the French foundation for medical research, the French national agency for research, the French national institute for research in public health (IRESP: TGIR cohorte santé 2008 program), the French ministry of health, the French ministry of research, the INSERM bone and joint diseases national research and human nutrition national research programs, Paris-Sud University, Nestlé, the French national institute for population health surveillance, the French national institute for health education, the European Union FP7 programs (2007-2013; HELIX, ESCAPE, ENRIECO, and Medall projects), the French diabetes national research program through a collaboration with the French association of diabetic patients, the French agency for environmental health safety (now ANSES), the Mutuelle Générale de l'Education Nationale (a complementary health insurance), the French national agency for food security, and the French-speaking association for the study of diabetes and metabolism. Family and Children of Ukraine (FCOU): Supported by the Fogarty International Center at the US National Institutes of Health, the US National Institute of Environmental Health Sciences, the US Centers for Disease Control and Prevention, the US Environmental Protection Agency, and the National Academy of Medical Sciences of Ukraine. Genetica e Ambiente: Studio Prospettico dell'Infanzia in Italia (GASPII): Supported by the Italian ministry of health. Groningen Expert Center for Kids with Obesity (GECKO Drenthe): Supported by an unrestricted grant from Hutchison Whampoa Ltd and funding from the University of Groningen, Well Baby Clinic Foundation Icare, Noordlease, the Paediatric Association of the Netherlands, and Youth Health Care Drenthe. Genetics of Glucose regulation in Gestation and Growth (Gen3G): Supported by operating grant 20697 from the Fonds de recherche du Québec en santé, operating grant MOP 115071 from the Canadian Institute of Health Reseach, a grant from Diabète Québec, and operating grant OG-3-08-2622-JA from the Canadian Diabetes Association. Generation R: The general design of the study received financial support from Erasmus MC, University Medical Center Rotterdam, Erasmus University Rotterdam, the Netherlands Organization for Health Research and Development, the Netherlands Organisation for Scientific Research and the Ministry of Health, Welfare, and Sport, and the Ministry of Youth and Families. The research leading to these results received funding from the European Union Horizon
2020 Research and Innovation Programme under grant 733206 (LifeCycle Project). Dr Jaddoe received grant ERC-2014-CoG-648916 from the European Research Council. Dr Gaillard received grant 2017T013 from the Dutch Heart Foundation, grant 2017.81.002 from the Dutch Diabetes Foundation, and grant 543003109 from the Netherlands Organisation for Health Research and Development. Generation XXI: Funded by Programa Operacional de Saúde-Saúde XXI, Quadro Comunitário de Apoio III and Administração Regional de Saúde Norte (Regional Department of Ministry of Health), by POCI-01-0145-FEDER-016837 through the Operational Programme Competitiveness and Internationalization and national funding from the Foundation for Science and Technology (Portuguese Ministry of Science, Technology, and Higher Education) under the project PathMOB, by FCT PTDC/DTP-EPI/3306/2014 (Risco cardiometabólico na infância: desde o início da vida ao fim da infância) by POCI-01-0145-FEDER-006862 and UID/DTP/ 04750/2013 (Unidade de Investigação em Epidemiologia-Instituto de Saúde Pública da Universidade do Porto), and FCT investigator contract IF/01060/2015 awarded to Dr A. C. Santos. Growth, Exercise and Nutrition Epidemiological Study In preSchoolers (GENESIS): Supported by a research grant from Friesland Hellas. German Infant Nutritional Intervention plus environmental and genetic influences (GINIplus): Supported for the first 3 years by the Federal Ministry for Education, Science, Research, and Technology (intervention group) and Helmholtz Zentrum Munich (observation group). The 4-, 6-, 10-, and 15-year follow-up examinations were covered from the respective budgets of the 5 study centers (Helmholtz Zentrum Munich, Research Institute at Marien-Hospital Wesel, LMU Munich, TU Munich, IUF-Leibniz Research-Institute for Environmental Medicine at the University of Düsseldorf) and by funding from the European Commission 7th Framework Programme (MeDALL project), Mead Johnson, and Nestlé and grant FKZ 20462296 from the Federal Ministry for Environment (awarded to IUF Düsseldorf). Norwegian Human Milk Study (HUMIS): Funded by award FP7/2007-2013 from the European Commission 7th Framework Programme, grant 289346 from European Union EarlyNutrition project, and by funds for project 213148 from the Norwegian Research Council's MILPAAHEL programme. INfancia y Medio Ambiente (INMA)-Sabadell: Funded by grant Red INMA G03/176 from the Instituto de Salud Carlos III in Spain and grant 1999SGR 00241 from the Generalitat de Catalunya-CIRIT. INMA-Valencia: Funded by grants FP7-ENV-2011 cod 282957 and HEALTH.2010.2.4.5-1 from the European Commission, grants G03/176, FIS-FEDER PI09/ O2647, PI11/01007, PI11/02591, PI11/02038, PI13/ 1944, PI13/2032, PI14/00891, PI14/01687, PI16/1288, Miguel Servet FEDER CP11/00178, CP15/00025, and CPII16/00051 from the Instituto de Salud Carlos III in Spain, and grants UGP 15-230, UGP-15-244, and UGP-15-249 from the Generalitat Valenciana, Foundation for the Promotion of Health and Biomedical Research of Valencia Region. INMA-Gipuzkoa: Funded by grants FISFIS PI06/0867, FIS-PSO9/0009 0867, and Red INMA G03/176 from the Instituto de Salud Carlos III in Spain, grants 2005111093 and 2009111069 from the Departamento de Salud del Gobierno Vasco, and grants DFG06/004 and FG08/001 from the Provincial Government of Guipúzcoa. INMA-Menorca: This study was funded by grant Red INMA G03/176 from the Instituto de Salud Carlos III in Spain. Child, parents and health: lifestyle and genetic constitution (KOALA): Data collection from pregnancy up to the age of 1 year was supported by grants from Royal Friesland Foods, the Triodos Foundation, the Phoenix Foundation, the Raphaël Foundation, the lona Foundation, the Foundation for the Advancement of Heilpedagogie, the Netherlands Organisation for Health Research and Development (2100.0090), the Netherlands Asthma Foundation (3.2.03.48 and 3.2.07.022), and the Netherlands Heart Foundation (2008B112). Krakow Cohort: Funded by grants R01ES010165 and R01ES015282 from the US National Institute of Environmental Health Sciences and by funding from the Lundin Foundation, the John and Wendy Neu Family Foundation, the Gladys and Roland Harriman Foundation, and the Anonymous Foundation. Influences of Lifestyle-Related Factors on the Immune System and the Development of Allergies in Childhood plus the influence of traffic emissions and genetics (LISAplus): Mainly supported by grants for the first 2 years from the Federal Ministry for Education, Science, Research, and Technology, the Helmholtz Zentrum Munich, the Helmholtz Centre for Environmental Research-UFZ, the Research Institute at Marien-Hospital Wesel, and a pediatric practice in Bad Honnef. The 4-, 6-, 10-, and 15-year follow-up examinations were funded by the respective budgets of the involved partners (the Helmholtz Zentrum Munich, the Helmholtz Centre for Environmental Research-UFZ, the Research Institute at Marien-Hospital Wesel, a pediatric practice in Bad Honnef, and the IUF-Leibniz-Research Institute for Environmental Medicine at the University of Düsseldorf), by grant FKZ 20462296 from the Federal Ministry for Environment (awarded to IUF Düsseldorf), and by support from the European Commission 7th Framework Programme (MeDALL project). LUKAS Cohort: Funded by EVO/VTR grants, grants 139021 and 287675 from the Academy of Finland, grant QLK4-CT-2001-00250 from the European Union, and funding from the Juho Vainio Foundation, the Foundation for Pediatric Research, the Päivikki and Sakari Sohlberg Foundation, the Finnish Cultural Foundation, and the National Institute for Health and Welfare in Finland. Norwegian Mother and Child Cohort Study (MoBa): Supported by the Norwegian Ministry of Health and Care Services and the Ministry of Education and Research, contract NO1-ES-75558 with the US National Institute of Environmental Health Sciences, and grants UO1 NS 047537-01 and U01 NS 047537-06A1 from the US National Institute of Neurological Disorders and Stroke. Nascita e INFanzia: gli Effetti dell'Ambiente (NINFEA): Partially funded by the Compagnia San Paolo Foundation and by the Piedmont Region. Prevention and Incidence of Asthma and Mite Allergy (PIAMA): Supported by the Organization for Health Research and Development, the Organization for Scientific Research, the Asthma Fund, the Ministry of Spatial Planning, Housing, and the Environment, and the Ministry of Health, Welfare, and Sport (all organizations in the Netherlands). Piccolipiù Project: Financially supported by CCM grants during 2010 and 2014 from the Italian National Center for Disease Prevention and Control and funding (art 12 and 12 bis D.lgs 502/92) from the Italian Ministry of Health. PRegnancy and Infant DEvelopment (PRIDE Study): Supported by grants from the Netherlands Organization for Health Research and Development, the Radboud Institute for Health Sciences, and the Lung Foundation Netherlands. Project Viva: Funded by grants 
R01 HD034568 and UG3OD023286 from the US National Institutes of Health. Polish Mother and Child Cohort Study (REPRO_PL): Funded by grants DEC-2014/15/B/NZ7/00998 and FP7 HEALS 603946 from the National Science Centre in Poland and grant 3068/7.PR/2014/2 from the Polish Ministry of Science and Higher Education. Exposure of Preschool-Age Greek Children (RHEA): Financially supported by European Commission projects FP6-2003-Food-3-NewGeneris, FP6-STREP Hiwate, FP7-ENV.2007.1.2.2.2, FP7-2008-ENV-1.2.1.4 Envirogenomarkers, FP7-HEALTH-2009-single stage CHICOS, FP7-ENV.2008.1.2.1.6, FP7-HEALTH-2012, and 211250-Escape and proposals 226285 ENRIECO and 308333 HELIX and by the Greek Ministry of Health. Slovak PCB Study: Support was provided by grants R01 CA096525, R03 TW007152, P30 ESO01247, P3O ESO23513, and K12 ESO19852 from the US National Institutes of Health. STEPS: This study was supported by the University of Turku, Abo Akademi University, the Turku University Hospital, the City of Turku, the Juho Vainio Foundation, and the Yrjö Jahnsson Foundation and by grants 121569 and 123571 from the Academy of Finland. Southampton Women's Survey (SWS): Supported by funding from the Medical Research Council, the National Institute for Health Research Southampton Biomedical Research Centre, the University of Southampton, Dunhill Medical Trust, and the University Hospital Southampton National Health Service Foundation Trust, FP7/2007-2013 from the European Commission 7th Framework Programme, and grant 289346 from the European Union EarlyNutrition project.

Role of the Funder/Sponsor: Investigators from the US National Institute of Environmental Health Sciences were only involved in the design of the birth outcomes phase of the FCOU study. All of the other funders had no role in the design and conduct of the study; collection, management, analysis, and interpretation of the data; preparation, review, or approval of the manuscript; and decision to submit the manuscript for publication.

Additional Contributions: ALSPAC: We are extremely grateful to all the families who took part in this study, the midwives for their help in recruiting them, and the whole team, which includes interviewers, computer and laboratory technicians, clerical workers, research scientists, volunteers, managers, receptionists, and nurses. $D N B C$ : We thank all the families for participating. $E D E N$ : We thank the mother-child cohort study group. FCOU: We acknowledge the individuals at the Louise Hamilton Kyiv Data Management Center (located within the School of Public Health, University of Illinois, Chicago) for their assistance in the data management. GASPII: We acknowledge the families involved. GECKO Drenthe: We are grateful for the participating families, the whole study team, and particularly the midwives, gynecologists, nurses, and general practioners for their help in the recruitment and measurement of participants. Gen3G: We acknowledge the support from clinical and research staff with blood sampling in the pregnancy clinic and for their help with recruitment along with the biomedical laboratory for performing the assays (all located at Centre Hospitalier Universitaire de Sherbrooke) Generation R: We gratefully acknowledge the contribution of the general practitioners, hospitals, midwives, and pharmacies in Rotterdam. Generation XXI: We gratefully acknowledge the families for their kindness, all the members of the research team for their enthusiasm and perseverance, and the participating hospitals and their staff for their help and support. GENESIS: We thank the research group for their contribution in the execution and completion of the study. GINIplus: We thank all the participating families and all the members of the study group for their excellent work. HUMIS: We thank the mothers who participated in the study and the Norwegian Research Council. INMA-Valencia: We particularly thank all the participants for their generous collaboration. INMA-Gipuzkoa: We thank the children and parents who participated. INMA-Menorca: We thank all the participants for their generous collaboration. KOALA: We thank the children and parents who participated. Krakow Cohort: We acknowledge the teams from Jagiellnonian University Medical College (W. Jedrychowski, MD, PhD, coinvestigator) and Columbia University (F. P. Perera, PhD, principal investigator). Drs Jedrychowski and Perera initiated the cohort and were awarded grants. LISAplus: We thank the participating families and the members of the study group for their excellent work. LUKAS: We thank all the participating families. $M o B a$ : We are grateful to all the participating families in Norway who continue to take part in this ongoing study. NINFEA: We thank all the participating families. PÉLAGIE: We thank the gynecologists, obstetricians, ultrasonographers, midwives, pediatricians, and families who participated. PIAMA: We thank the participants for their ongoing collaboration. Piccolipiù: We acknowledge the working group and the families involved in the study. PRIDE Study: We thank the mothers and infants who continue to participate in this ongoing study as well as all the midwives, gynecologists, and general practitioners for thei contributions to the data collection. Project Viva: We thank the mothers, children, and families for their ongoing participation. REPRO_PL: We particularly thank all the cohort participants for their collaboration. RHEA: We particularly thank all the cohort participants for their generous collaboration. Slovak PCB Study: We thank the study participants for their ongoing cooperation. STEPS: We are grateful to all the families who took part. SWS: We are grateful to the women of Southampton who gave their time to take part in the survey and to the research nurses and other staff who collected and processed the data.

\section{REFERENCES}

1. Goldstein RF, Abell SK, Ranasinha S, et al. Association of gestational weight gain with maternal and infant outcomes: a systematic review and meta-analysis. JAMA. 2017;317(21):2207-2225 doi:10.1001/jama.2017.3635

2. Nehring I, Schmoll S, Beyerlein $A$, Hauner $H$, von Kries R. Gestational weight gain and long-term postpartum weight retention: a meta-analysis. Am J Clin Nutr. 2011;94(5):1225-1231. doi:10.3945/ajcn. 111.015289

3. Mamun $A A$, Mannan M, Doi SA. Gestationa weight gain in relation to offspring obesity over the life course: a systematic review and bias-adjusted meta-analysis. Obes Rev. 2014;15(4):338-347. doi: 10.1111/obr.12132

4. Gaillard R. Maternal obesity during pregnancy and cardiovascular development and disease in the offspring. Eur J Epidemiol. 2015;30(11):1141-1152. doi:10.1007/s10654-015-0085-7
5. Aune D, Saugstad OD, Henriksen T, Tonstad S. Maternal body mass index and the risk of fetal death, stillbirth, and infant death: a systematic review and meta-analysis. JAMA. 2014;311(15):1536 1546. doi:10.1001/jama.2014.2269

6. Yu Z, Han S, Zhu J, Sun X, Ji C, Guo X. Pre-pregnancy body mass index in relation to infant birth weight and offspring overweight/obesity: a systematic review and meta-analysis. PLoS One. 2013;8(4):e61627. doi:10.1371/journal.pone.0061627

7. Institute of Medicine and National Research Council Committee to Reexamine IOM Pregnancy Weight Guidelines. Weight Gain During Pregnancy: Reexamining the Guidelines. Washington, DC: Institute of Medicine; 2009.

8. Santos S, Eekhout I, Voerman E, et al. Gestational weight gain charts for different body mass index groups for women in Europe, North America, and Oceania. BMC Med. 2018;16(1):201. doi:10.1186/s12916-018-1189-1

9. Patro Golab B, Santos S, Voerman E, Lawlor DA Jaddoe VWV, Gaillard R; MOCO Study Group Authors. Influence of maternal obesity on the association between common pregnancy complications and risk of childhood obesity: an individual participant data meta-analysis. Lancet Child Adolesc Health. 2018;2(11):812-821. doi:10. 1016/S2352-4642(18)30273-6

10. World Health Organization. Body mass index. http://www.euro.who.int/en/health-topics/diseaseprevention/nutrition/a-healthy-lifestyle/bodymass-index-bmi. Accessed October 25, 2016.

11. Niklasson A, Ericson A, Fryer JG, Karlberg J, Lawrence C, Karlberg P. An update of the Swedish reference standards for weight, length and head circumference at birth for given gestational age (1977-1981). Acta Paediatr Scand. 1991;80(8-9): 756-762. doi:10.1111/j.1651-2227.1991.tb11945.x

12. World Health Organization Multicentre Growth Reference Study Group. WHO child growth standards based on length/height, weight and age. Acta Paediatr Suppl. 2006;450:76-85.

13. de Onis M, Onyango AW, Borghi E, Siyam A Nishida C, Siekmann J. Development of a WHO growth reference for school-aged children and adolescents. Bull World Health Organ. 2007;85(9): 660-667. doi:10.2471/BLT.07.043497

14. Cedergren MI. Optimal gestational weight gain for body mass index categories. Obstet Gynecol. 2007:110(4):759-764. doi:10.1097/01.AOG 0000279450.85198.b2

15. Steyerberg EW. Clinical Prediction Models: A Practical Approach to Development, Validation, and Updating. Berlin/Heidelberg, Germany: Springer Science and Business Media; 2008.

16. Bracero LA, Byrne DW. Optimal maternal weight gain during singleton pregnancy. Gynecol Obstet Invest. 1998;46(1):9-16. doi:10.1159/ 000009988

17. Beyerlein A, Schiessl B, Lack N, von Kries R Optimal gestational weight gain ranges for the avoidance of adverse birth weight outcomes: a novel approach. Am J Clin Nutr. 2009;90(6):1552 1558. doi:10.3945/ajcn.2009.28026

18. Oken E, Kleinman KP, Belfort MB, Hammitt JK, Gillman MW. Associations of gestational weight gain with short- and longer-term maternal and child health outcomes. Am J Epidemiol. 2009;170(2): 173-180. doi:10.1093/aje/kwp101 
19. Langford A, Joshu C, Chang JJ, Myles T, Leet T. Does gestational weight gain affect the risk of adverse maternal and infant outcomes in overweight women? Matern Child Health J. 2011;15 (7):860-865. doi:10.1007/s10995-008-0318-4

20. DeVader SR, Neeley HL, Myles TD, Leet TL. Evaluation of gestational weight gain guidelines for women with normal prepregnancy body mass index. Obstet Gynecol. 2007;110(4):745-751. doi:10. 1097/01.AOG.0000284451.37882.85

21. Kiel DW, Dodson EA, Artal R, Boehmer TK, Leet TL. Gestational weight gain and pregnancy outcomes in obese women: how much is enough? Obstet Gynecol. 2007;110(4):752-758. doi:10.1097/ 01.AOG.0000278819.17190.87
22. Hutcheon JA, Bodnar LM. A systematic approach for establishing the range of recommended weight gain in pregnancy. Am J Clin Nutr. 2014;100(2):701-707. doi:10.3945/ajcn.114.085258

23. Thangaratinam $S$, Rogozińska $E$, Jolly $K$, et al. Interventions to reduce or prevent obesity in pregnant women: a systematic review. Health Technol Assess. 2012;16(31):iii-iv, 1-191. doi:10.3310/ hta16310

24. Dodd JM, Turnbull D, McPhee AJ, et al; LIMIT Randomised Trial Group. Antenatal lifestyle advice for women who are overweight or obese: LIMIT randomised trial. BMJ. 2014;348:g1285. doi:10. 1136/bmj.g1285
25. Poston L, Bell R, Croker H, et al; UPBEAT Trial Consortium. Effect of a behavioural intervention in obese pregnant women (the UPBEAT study): a multicentre, randomised controlled trial. Lancet Diabetes Endocrinol. 2015;3(10):767-777. doi:10. 1016/S2213-8587(15)00227-2

26. International Weight Management in Pregnancy (i-WIP) Collaborative Group. Effect of diet and physical activity based interventions in pregnancy on gestational weight gain and pregnancy outcomes: meta-analysis of individual participant data from randomised trials. BMJ. 2017; 358:j3119.

\section{Prepregnancy Body Mass Index, Weight Gain During Pregnancy, and Health Outcomes}

Mary M. McDermott, MD; Linda Brubaker, MD

Each year, approximately 130 million infants are born worldwide, and there were 3.8 million births in the United States in 2017. ${ }^{1}$ Rates of maternal mortality and adverse pregnancy out-

$\leftarrow$ Related article page 1702 comes in the United States are increasing, and abnormal prepregnancy body mass index (BMI) and abnormal gestational weight gain have been associated with these adverse outcomes.

In a recent meta-analysis published in JAMA, Goldstein et $\mathrm{al}^{2}$ reported that gestational weight gain exceeded weight gain recommended by the Institute of Medicine (now the National Academy of Medicine) in 47\% of 1309136 pregnancies. Women with excess gestational weight gain were more likely to undergo cesarean delivery (odds ratio [OR], 1.30 [95\% CI, 1.25-1.35]; absolute difference: $4 \%$ ) and more likely to have infants who were large for gestational age (OR, 1.85 [95\% CI, 1.76-1.95]; absolute difference: $4 \%$ ) or who met criteria for macrosomia (OR, 1.95 [95\% CI, 1.79-2.11]; absolute difference: 6\%). ${ }^{2}$

In this issue of JAMA, the LifeCycle Project-Maternal Obesity and Childhood Outcomes Study Group ${ }^{3}$ reports the results of an individual patient-level meta-analysis in which the amount of gestational weight gain associated with fewer adverse pregnancy outcomes was defined according to prepregnancy BMI. Even though the amount of optimal weight gain during pregnancy varied according to prepregnancy BMI, gestational weight gain had only low to moderate discriminative performance for adverse outcomes.

In contrast, prepregnancy BMI values above normal were strongly associated with higher rates of adverse outcomes. These associations were observed regardless of the amount of gestational weight gain. Thus, an important conclusion of the report by Voerman et $\mathrm{al}^{3}$ is that prepregnancy BMI was more strongly associated with adverse maternal and infant outcomes than the amount of gestational weight gain.

Obesity affects $40 \%$ of women in the United States. ${ }^{4}$ Ensuring that pregnancies result in healthy mothers and infants is an important public health goal. Based on the study by Voerman et al, ${ }^{3}$ resources should be dedicated toward ensuring an optimal BMI for all women of reproductive age rather than on gestational weight gain. ${ }^{5}$ Recent guidelines and available services can help achieve this important public health goal. ${ }^{5,6}$
Author Affiliations: Division of General Internal Medicine, Northwestern University Feinberg School of Medicine, Chicago, Illinois (McDermott); Senior Editor, JAMA (McDermott); University of California San Diego, La Jolla, California (Brubaker); Associate Editor, JAMA (Brubaker).

Corresponding Author: Mary M. McDermott, MD, Division of General Internal Medicine, Northwestern University Feinberg School of Medicine, 750 N Lake Shore Dr, Chicago, IL 60611 (mdm608@northwestern.edu).

Conflict of Interest Disclosures: Dr McDermott reported receiving funding from Viromed, Hershey Company, Chromadex, and ReserveAge; and receiving grants from Regeneron. Dr Brubaker reported receiving personal fees from the Female
Pelvic Medicine and Reconstructive Surgery and UpToDate.

1. Hamilton BE, Martin JA, Osterman MJK, Driscoll AK, Rossen LM. Births: provisional data for 2017. https://www.cdc.gov/nchs/data/vsrr/report004. pdf. Accessed March 28, 2019.

2. Goldstein RF, Abell SK, Ranasinha S, et al. Association of gestational weight gain with maternal and infant outcomes: a systematic review and meta-analysis. JAMA. 2017;317(21):2207-2225. doi:10.1001/jama.2017.3635

3. LifeCycle Project-Maternal Obesity and Childhood Outcomes Study Group. Association of gestational weight gain with adverse maternal and infant outcomes [published online May 7, 2019]. JAMA. doi:10.1001/jama.2019.3820
4. Hales CM, Fryar CD, Carroll MD, Freedman DS, Ogden CL. Trends in obesity and severe obesity prevalence in US youth and adults by sex and age, 2007-2008 to 2015-2016. JAMA. 2018;319(16): 1723-1725. doi:10.1001/jama.2018.3060

5. Kahan S, Manson JE. Obesity treatment, beyond the guidelines: practical suggestions for clinical practice. JAMA. 2019;321(14):1349-1350. doi:10. 1001/jama.2019.2352

6. Curry SJ, Krist AH, Owens DK, et al; US Preventive Services Task Force. Behavioral weight loss interventions to prevent obesity-related morbidity and mortality in adults: US Preventive Services Task Force recommendation statement. JAMA. 2018; 320(11):1163-1171. doi:10.1001/jama.2018.13022 